\title{
Proteinograma do soro lácteo de ovelhas da raça Santa Inês em diferentes fases de lactação ${ }^{1}$
}

\author{
Vânia F. Lemos ${ }^{2 *}$, Eduardo L.S. Guaraná ${ }^{3}$, José A.B. Afonso ${ }^{4}$, José J. Fagliari ${ }^{5}$, \\ Paulo C. Silva ${ }^{5}$, Pierre C. Soares ${ }^{6}$ e Carla L. Mendonça ${ }^{4}$
}

\begin{abstract}
Lemos V.L., Guaraná E.L.S., Afonso J.A.B., Fagliari J.J., Silva P.C., Soares P.C. \& Mendonça C.L. 2013. [Proteinogram the whey protein of Santa Ines sheep breed in different stages of lactation.] Proteinograma do soro lácteo de ovelhas da raça Santa Inês em diferentes fases de lactação. Pesquisa Veterinária Brasileira 33(6):807-812. Clínica de Bovinos, Campus Garanhuns, Universidade Federal Rural de Pernambuco, Av. Bom Pastor s/n, Cx. Postal 152, Mundaú, Garanhuns, PE 55292-901, Brazil. E-mail: vanialemos91@gmail.com

This study aimed to evaluate the influence of lactation phases on the proteinogram of whey protein in Santa Inês ewes. Ewes were accompanied in a semi-intensive system using the same sanitary and nutritional management evaluated at 15, 30, 60 and 90 days postpartum (end of weaning and lactation). Clinical examination of the mammary gland was carried out through and bacteriological culture. The screening of the material resulted in 44 milk samples of healthy glands concurrent negative by CMT and bacteriological culture exam. For obtaining the whey protein renin solution was used. The whey was fractionated into aliquots and kept in the -80C freezer to later separation of protein fractions. For determination of total protein of whey protein was employed the biuret, observing the linearity of the test. Separation of protein fractions was performed, using polyacrylamide gel containing sodium dodecyl sulfate (SDS-PAGE). Eigth protein were observed including lactoferrin, serum albumin, IgA, IgG (heavy chain IgG (IgG CP), light chain IgG (IgG CL), $\beta$-lactoglobulin, $\alpha$-lactalbumin and proteins identified as PM 15000 and PM 29000. No significant difference was observed at different stages of lactation in the following protein: IgA ( $P>0.3895)$, lactoferrin $(\mathrm{P}>0.1611), \mathrm{PM} 29000$ $(\mathrm{P}>0.4879), \alpha$-lactalbumin $(\mathrm{P}>0.0799)$ and $\mathrm{PM} 15000(\mathrm{P}>0.4494)$. In total protein $(\mathrm{P}<0.0022)$, albumin protein $(\mathrm{P}<0.0377)$ and IgG $(\mathrm{P}<0.0354)$ it was observed a significant variation in the first moments of observations, in the $\beta$-lactoglobulin protein $(\mathrm{P}<0.0005)$ there was significant variation with reduction of 15 to 30 days postpartum with progressive elevation until the last stage of lactation ( 90 days postpartum). The SDS-PAGE technique allowed the quantification of eigth whey proteins in health ewes. The protein fractions identified reflect the profile of whey to ovine species, with influence of stages of lactation in albumin, IgG and $\beta$-lactoglobulin.
\end{abstract}

INDEX TERMS: Proteinogram, whey protein, postpartum, lactation, small ruminants, milk, SDS-PAGE.

RESUMO.- No presente estudo objetivou-se avaliar a influência das fases de lactação sobre o proteinograma do soro lácteo de ovelhas da raça Santa Inês. Foram acompanha-

\footnotetext{
${ }^{1}$ Recebido em 22 de setembro de 2012.

Aceito para publicação em 26 de janeiro de 2013.

Parte da Dissertação do primeiro autor no Programa de Pós-Graduação em Sanidade e Reprodução de Ruminantes, Universidade Federal Rural de Pernambuco (UFRPE).

${ }^{2}$ Programa de Pós-Graduação em Sanidade e Reprodução em Ruminantes, UFRPE, Av. Bom Pastor s/n. Caixa Postal 152, Boa Vista, Garanhuns, PE 55292-270, Brasil. *Autor para correspondência: vanialemos91@gmail.com

${ }^{3}$ Programa de Pós-Graduação em Ciência Veterinária, UFRPE, Av. Dom Manoel de Medeiros s/n, Dois Irmãos, Recife, PE 52171-030.
}

das ovelhas em sistema de criação semi-intensivo com o mesmo manejo higiênico, sanitário e nutricional avaliadas aos 15, 30, 60 e 90 dias após o parto (final da lactação

\footnotetext{
${ }^{4}$ Clínica de Bovinos, Campus Garanhuns, Universidade Federal Rural de Pernambuco, Avenida Bom Pastor s/n, Caixa Postal 152, Boa Vista, Garanhuns, PE 55292-270. E-mail: carlalopes.mendonca@gmail.com

${ }^{5}$ Departamento de Clínica e Cirurgia Veterinária, Faculdade de Ciências Agrárias e Veterinária, Universidade Estadual Paulista (Unesp), Campus Jaboticabal, Via de acesso Prof. Paulo Donato Castellane s/n, Jaboticabal, SP 14884-900, Brasil.

${ }^{6}$ Departamento de Medicina Veterinária, Universidade Federal Rural de Pernambuco, Avenida Dom Manoel de Medeiros s/n, Caixa Postal 152, Dois Irmãos, Recife, PE.
} 
e desmame). Procedeu-se ao exame clínico da glândula mámaria e triagem e cultivo bacteriológico. A triagem do material resultou em 44 amostras de leite de glândulas sadias baseadas no exame negativo simultâneo do CMT e do bacteriológico. Para a obtenção do soro lácteo utilizou-se solução de renina. 0 soro lácteo foi fracionado em alíquotas e mantido em freezer a $-80^{\circ} \mathrm{C}$ para posterior separação das frações protéicas. Para determinação da proteína total do soro lácteo empregou-se o biureto. A separação das frações protéicas foi realizada utilizando-se eletroforese em gel de poliacrilamida contendo dodecil sulfato de sódio (SDS-PAGE). Foram observadas oito proteínas entre elas lactoferrina, albumina sérica, IgA, IgG ( IgG de cadeia pesada - IgG CP e IgG de cadeia leve - IgG CL), $\beta$-lactoglobulina, $\alpha$-lactoalbumina e as proteínas identificadas como PM 15.000 Da e PM 29.000 Da. Não foi observada diferença significativa nas diferentes fases de lactação nas seguintes proteínas: $\operatorname{IgA}(\mathrm{P}>0,3895)$, lactoferrina $(\mathrm{P}>0,1611)$, PM $29000(\mathrm{P}>0,4879), \alpha$ - lactoalbumina $(\mathrm{P}>0,0799)$ e $\mathrm{PM}$ $15000(\mathrm{P}>0,4494)$. Na proteína total $(\mathrm{P}<0,0022)$ e nas proteínas albumina $(\mathrm{P}<0,0377), \operatorname{IgG}(\mathrm{P}<0,0354)$ verificou-se variação significativa nos primeiros momentos de observação, na proteína $\beta$-lactoglobulina $(P<0,0005)$ verificou-se variação significativa com diminuição dos 15 até 30 dias pós parto com elevação progressiva até a última fase de lactação (90 dias pós parto). A técnica de SDS-PAGE permitiu a quantificação de oito proteínas no soro lácteo de ovelhas sadias. As proteínas identificadas refletem o perfil do soro lácteo para a espécie ovina, havendo influência das fases da lactação na concentração albumina, IgG e $\beta$-lactoglobulina.

TERMOS DE INDEXAÇÃO: Proteinograma, soro lácteo, pós-parto, lactação, pequenos ruminantes, leite, SDS-PAGE.

\section{INTRODUÇÃO}

As proteínas do leite, na sua grande maioria, são sintetizadas na própria glândula mamária, pelas células secretoras alveolares ou têm origem plasmática. A caseína responde por mais de $80 \%$ da constituição das proteínas totais do leite e a proporção relativa das proteínas do soro lácteo frente à caseína variam segundo o estágio de lactação. Geralmente o leite produzido nos primeiros dias depois do parto e no final da lactação tem um conteúdo de proteínas do soro superior ao leite da fase intermediária da lactação. Este incremento está acompanhado de níveis elevados de proteínas oriundas do soro sanguíneo (Varnam \& Sutherland 1995).

A exata composição das proteínas lácteas varia entre as espécies animais, sendo que a maioria (80\% a 95\%) é sintetizada nas células epiteliais da glândula mamária incluindo a caseína, $\alpha$-lactoalbumina, $\beta$-lactoglobulina e lactoferrina, enquanto que as imunoglobulinas e a albumina sérica são proteínas derivadas do sangue e incorporadas às células epiteliais da glândula mamária (Burgoyne \& Duncan 1998, Cozma et al. 2011). Geralmente durante as fases de lactação, os principais componentes do leite de ovelha variam seguindo uma curva inversa a da produção de leite, as concentrações de gordura, sólidos totais (caseína e proteínas do soro lácteo) se elevam no início e final da lactação e se encontram em baixos níveis no meio da lactação, quando a produção de leite é máxima (Bencini 2001, Velasco et al. 2001).

A concentração das proteínas e peptídeos presentes no leite pode ser influenciada por vários fatores, dentre os quais a raça, o estado de saúde, as fases da lactação, o sistema de alimentação, bem como o sistema e frequência de ordenha (Gopal \& Gill, 2000).

Na secreção láctea da ovelha e da cabra, as principais proteínas presentes no leite são similares àquelas encontradas no leite da vaca. A caracterização das proteínas ocorre em duas fases distintas, uma na fase micelar composta pela caseína, a outra nas proteínas do soro lácteo $(\alpha$-lactoalbumina, $\beta$-lactoglobulinas, imunoglobulinas e albumina sérica (Borková \& Snaselová 2005, Park et al. 2007).

O período após o parto é caracterizado por mudanças significativas na glândula mamária, entre as quais a produção do colostro, que apresenta composição diferente da secreção láctea obtida quando o animal está em plena lactação; esta situação ocorre como decorrência de alterações na concentração das proteínas do sangue para o colostro e do colostro ao leite durante o pós-parto (Schalm et al. 1971, Levieux \& Ollier 1999).

A eletroforese em gel de poliacrilamida contendo dodecil sulfato de sódio (SDS-PAGE) é uma técnica também empregada na separação das proteínas do leite, permitindo a identificação de várias frações protéicas, bem como sua quantificação, propiciando a visualização de 20 a 30 proteínas com pesos moleculares que variam entre 24.000 a 340.000 dáltons (Da) (Fagliari \& Silva 2002, Patel et al. 2007). A caracterização, tanto sob o ponto de vista qualitativo, como quantitativo das proteínas do soro lácteo, está documentada na vaca (Sant'ana 2004, Raimondo et al. 2009, Rocha et al. 2009) e na cabra (Raimondo et al. 2011), no entanto em ovelhas a literatura é bastante escassa, particularmente se tratando do acompanhamento em diferentes estágios da lactação.

Diante do exposto, este estudo tem por objetivo avaliar a influência das fases de lactação sobre o proteinograma do soro lácteo de ovelhas da raça Santa Inês hígidas.

\section{MATERIAL E MÉTODOS}

Foram avaliadas ovelhas da raça Santa Inês, oriundas de rebanho comercial da região, criadas em sistema de manejo semi-intensivo sob as mesmas condições higiênicas, sanitárias e nutricionais, acompanhadas em diferentes fases de lactação (15 dias, 30 dias, 60 dias e 90 dias após o parto, período em que era estabelecido o desmame na região).

0 exame clínico dos animais e das respectivas glândulas mamárias foi realizado em todos os momentos experimentais e seguiu as recomendações de Diffay et al. (2005). Os resultados do California Mastitis Test (CMT) foram interpretados de acordo com Shalm et al. (1971)

As ovelhas selecionadas para este estudo $(n=11)$ e as respectivas glândulas acompanhadas ao longo das quatro fases de lactação $(n=44)$, foram triadas após resultado simultâneo negativo no CMT e no cultivo bacteriológico do leite, bem como no exame clínico das glândulas, caracterizando a higidez da glândula mamária. 
Inicialmente foram colhidos dez $\mathrm{mL}$ de leite para realização do proteinograma e posteriormente, após rigorosa antissepsia do óstio do teto com álcool a 70\%, aproximadamente três $\mathrm{mL}$ de leite em tubos esterilizados para realização do exame bacteriológico.

As amostras foram acondicionadas sob refrigeração, em caixa de material isotérmico e transportadas ao laboratório para processamento. 0 cultivo bacteriológico foi realizado seguindo as recomendações do National Mastitis Council (1990) e a caracterização bioquímica de acordo com Quinn et al. (1994).

As amostras de leite empregadas no perfil eletroforético foram estocadas e mantidas em ultrafreezer ${ }^{7} \mathrm{a}-80^{\circ} \mathrm{C}$.

Para a realização do proteinograma obteve-se o soro lácteo empregando-se a técnica descrita por Schalm et al. (1971) adotando-se algumas adaptações em decorrência da menor quantidade de leite produzido pela ovelha, quando comparado à vaca, conforme descrito a seguir. Inicialmente as amostras de leite após o descongelamento em banho-maria a $37^{\circ} \mathrm{C}$ foram homogeneizadas em vortex ${ }^{8}$; para cada $1.000 \mu \mathrm{L}$ de leite foram adicionados $75 \mu \mathrm{L}$ de solução de renina ${ }^{9}$ mantidos em banho maria a $37^{\circ} \mathrm{C}$ por aproximadamente 20 minutos e centrifugadas a $21.000 \mathrm{G}$ durante dez minutos em centrífuga refrigerada ${ }^{10}$. A fração intermediária, resultante da solução trifásica, correspondente ao soro lácteo, foi fracionada em tubos tipo eppendorf e mantidas em ultrafreezer ${ }^{18}$ a $-80^{\circ} \mathrm{C}$ para posterior separação das frações protéicas. A determinação da proteína total do soro lácteo foi realizada empregando-se reagente comercial ${ }^{11}$, observando-se a linearidade do teste.

A separação das proteínas lácteas foi realizada utilizando-se a técnica de eletroforese em gel de poliacrilamida contendo dodecil sulfato de sódio (SDS-PAGE), conforme descrito por Laemmli (1970) e Fagliari \& Silva (2002). Para a identificação das proteínas do soro lácteo foi empregada como referência solução marcadora $^{12}$ com diversos pesos moleculares (6.500-200.000 Da) e as proteínas purificadas lactoferrina, $\beta$-lactoglobulina e a $\alpha$-lactoalbumina bovinas. A determinação das concentrações protéicas foi obtida por meio de densitômetro computadorizado ${ }^{13}$. Em função do protocolo utilizado, a imunoglobulina G (IgG) foi separada em duas cadeias, cadeia leve (IgG CL) e cadeia pesada (IgG CP), decorrentes do uso do 2-mercaptoetanol na solução tampão, empregada na preparação das amostras para a corrida eletroforética em gel poliacrilamida contendo dodecil sulfato de sódio (SDS-PAGE).

Os resultados, que não atenderam as premissas de normalidade foram submetidos à transformação logarítmica de base dez e posteriormente a análise de variância (ANOVA), utilizando-se o procedimento GLM do $\mathrm{SAS}^{14}$. As médias foram comparadas pela diferença mínima significativa (d.m.s.) do teste de Student Newman Keuls (SNK) ao nível de significância de 5\%.
As concentrações das imunoglobulinas IgA e IgG CL, bem como as proteínas de PM 15.000 Da e PM 29.000 Da não apresentaram distribuição normal, no entanto os resultados foram expressos em médias e desvios-padrão. A análise de regressão das proteínas identificadas no soro lácteo, que tiveram significância no teste F da ANOVA foi realizada em função dos momentos de avaliação correspondendo as fases de lactação, adotando o nível de 5\% de significância. A análise de correlação de Pearson foi realizada adotando o nível de $5 \%$ de significância, sendo considerada alta quando $r>0,60$; média quando $r>0,30$ e $<0,60$; e baixa quando $\mathrm{r}<0,30$ (Little \& Hill 1978).

0 trabalho obteve parecer favorável da Comissão de Ética no Uso de Animais (CEUA), da Universidade Federal Rural de Pernambuco com a licença 017/2010 (6029/2010 D08) CEPE/UFRPE de acordo com as normas do COBEA e National Institute of Health Guide for Care and Use of Laboratory Animals.

\section{RESULTADOS E DISCUSSÃO}

O fracionamento eletroforético do soro lácteo de glândulas mamárias sadias em diferentes fases de lactação, permitiu a observação de 11 a 22 proteínas com pesos moleculares variando entre 11.000 a $251.000 \mathrm{Da}$, propiciando a identificação/quantificação de oito proteínas de interesse, submetidas à análise estatística, entre elas: IgA, lactoferrina, albumina, IgG (IgG de cadeia pesada - IgG CP e IgG de cadeia leve - IgG CL), PM 29.000 Da, $\beta$-lactoglobulina, PM 15.000 Da e $\alpha$-lactoalbumina (Quadro 1).

A técnica de eletroforese em gel de poliacrilamida se revelou satisfatória na identificação e quantificação das proteínas presentes no soro lácteo das ovelhas, permitindo a

\footnotetext{
${ }^{7}$ Ultralow freezer NuAire Inc., 2100 Fernbrook Lane N. Plymouth, MN 55447, USA.

${ }^{8}$ Quimis Aparelhos Científicos Ltda, Rua Gema 278, Diadema, São Paulo, Brasil.

${ }^{9}$ Coalho Estrella ${ }^{\circledR}$, Chr. Hansen Brasil Ind. e Com. Ltda, Valinhos, São Paulo.

${ }^{10}$ Mikro 200R Hettich-Zentrifugern,Föhrenstr.12 D 78532 Tuttlingen, Germany.

${ }^{11}$ Proteína Total, Labtest Diagnóstica S.A., Av. Paulo Ferreira da Costa 600, Lagoa Santa, Minas Gerais, MG 33400-000, Brasil.

${ }^{12}$ Sigma Sigma- Aldrich Corporation, 3050 Spruce Street, St Louis, MO 63103, USA.

13 Shimadzu CS 9301, 1Nishinokyo-Kuwabara-cho, Nakagyo-ku, Kyoto 604-8511, Japan.

${ }^{14}$ Institute, Statistical Analysis Systems Institute Inc., Cary, 2000.
}

Quadro 1. Valores médios, desvios-padrão, média geral e níveis de significância da concentração das proteínas $(\mathrm{mg} / \mathrm{dL})$ identificadas no soro lácteo $(\mathrm{n}=44)$ de ovelhas Santa Inês em diferentes fases de lactação

\begin{tabular}{|c|c|c|c|c|c|c|}
\hline \multirow[t]{2}{*}{ Proteínas } & \multicolumn{4}{|c|}{ Fases de lactação } & \multirow{2}{*}{$\begin{array}{c}\text { Média } \\
\text { Geral }\end{array}$} & \multirow[t]{2}{*}{$\operatorname{Pr}>\mathrm{F}$} \\
\hline & 15 dias & 30 dias & 60 dias & 90 dias & & \\
\hline PT $(g / d L)$ & $1,91 \pm 0,20^{\mathrm{A}}$ & $1,64 \pm 0,16^{\mathrm{B}}$ & $1,82 \pm 0,14^{\mathrm{A}}$ & $1,91 \pm 0,17^{A}$ & 1,82 & 0,0022 \\
\hline Albumina & $140,40 \pm 49,21^{\mathrm{A}}$ & $89,76 \pm 39,48^{\mathrm{B}}$ & $89,46 \pm 44,51^{\mathrm{B}}$ & $99,05 \pm 48,89^{\mathrm{B}}$ & 104,64 & 0,0377 \\
\hline $\operatorname{IgA}$ & $3,69 \pm 2,57$ & $2,16 \pm 1,57$ & $2,93 \pm 1,98$ & $2,10 \pm 1,13$ & 2,72 & 0,3895 \\
\hline IgGCP & $117,77 \pm 56,29^{A}$ & $57,90 \pm 32,59^{в}$ & $62,46 \pm 21,95^{\text {в }}$ & $96,46 \pm 44,47^{\text {в }}$ & 83,65 & 0,0005 \\
\hline IgG CL & $45,04 \pm 27,11$ & $35,76 \pm 18,06$ & $48,66 \pm 30,51$ & $51,78 \pm 22,08$ & 45,01 & 0,3333 \\
\hline IgG Total & $162,81 \pm 76,802^{\mathrm{A}}$ & $93,66 \pm 42,05^{\text {в }}$ & $111,13 \pm 44,11^{\mathrm{AB}}$ & $148,24 \pm 44,16^{\mathrm{AB}}$ & 128,96 & 0,0354 \\
\hline Lactoferrina & $30,10 \pm 14,41$ & $19,88 \pm 9,20$ & $21,77 \pm 11,13$ & $25,12 \pm 7,46$ & 24,18 & 0,1611 \\
\hline PM $15.000 \mathrm{Da}$ & $5,97 \pm 5,36$ & $12,15 \pm 10,39$ & $12,71 \pm 3,68$ & $17,24 \pm 4,92$ & 12,10 & 0,4494 \\
\hline PM $29.000 \mathrm{Da}$ & $82,43 \pm 56,01$ & $57,36 \pm 32,94$ & $68,30 \pm 36,89$ & $82,23 \pm 41,07$ & 71,61 & 0,4879 \\
\hline$\beta$ lactoglobulina & $1137,05 \pm 154,98^{\mathrm{BC}}$ & $1022,43 \pm 104,65^{\mathrm{C}}$ & $1215,38 \pm 123,19^{\mathrm{AB}}$ & $1300,01 \pm 162,83^{A}$ & 168,72 & 0,0005 \\
\hline$\alpha$ lactoalbumina & $311,44 \pm 116,80$ & $318,06 \pm 136,93$ & $271,77 \pm 70,61$ & $206,29 \pm 55,03$ & 280,25 & 0,0799 \\
\hline
\end{tabular}


detecção de concentrações mínimas proteícas, assim como realizado anteriormente na vaca (Sant'ana 2004; Raimondo et al. 2009, Rocha et al. 2009) e na cabra (Raimondo et al. 2011).

Proteína total (PT).- No que diz respeito à concentração da proteína total do soro lácteo, foi observada diferença $(\mathrm{P}<0,0022)$ entre os estágios da lactação. As maiores concentrações foram verificadas na fase inicial $(1,91 \mathrm{~g} / \mathrm{dL})$ e final da lactação $(1,91 \mathrm{~g} / \mathrm{dL})$, apresentando os menores valores aos 30 dias da lactação (1,64g/dL) (Quadro 1, Fig.1). As maiores concentrações de proteína total nas fases inicial e final da lactação corroboram os achados de Bencini et al.

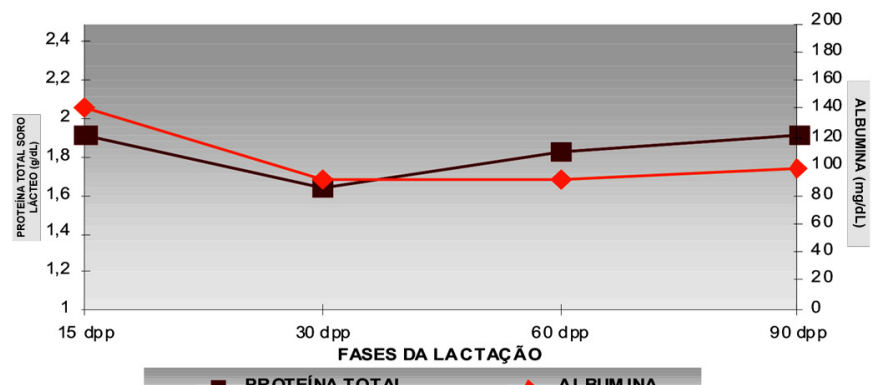

Fig.1. Valores médios da concentração da proteína total (g/dL) e da albumina $(\mathrm{mg} / \mathrm{dL})$, obtidos por SDS-PAGE, no soro lácteo de glândulas mamárias sadias de ovelhas Santa Inês em diferentes fases de lactação.

(2001) e Velasco et al. (2001), que observaram variação na concentração dos principais componentes do leite de ovelhas, que apresentaram um perfil inverso ao da produção de leite (início e final da lactação). Resultados semelhantes foram relatados em vacas por Auldist et al. (1995) que encontraram aumento das concentrações de proteína total do soro lácteo no início e no terço final da lactação, assim como na fase inicial aos citados por Sant'ana (2004) e Raimondo et al. (2009). Valores superiores de proteína total no soro lácteo de ovelhas foram relatados por Cozma et al. (2011) $(2,33 \mathrm{~g} / \mathrm{dL})$, independente da fase de lactação, provavelmente por empregarem outra metodologia.

Albumina sérica. As maiores concentrações de albumina foram observadas na fase inicial da lactação $(140,41 \mathrm{mg} /$ $\mathrm{dL})$, diminuindo significativamente $(\mathrm{P}<0,0377)$ até o $30^{\circ}$ 잉 dia e permanecendo estável até a fase final ( 90 dias pós parto), quando apresentou discreto aumento (Quadro 1, Fig.1). Confrontando estes achados com a literatura pesquisada, verificou-se que os valores obtidos neste estudo foram superiores aos descritos por Nudda et al. (2003) $(61,0 \mathrm{mg} / \mathrm{dL})$, também em ovelhas, no entanto, empregando outro protocolo na técnica SDS PAGE.

Sant'ana (2004) avaliando o soro lácteo de vacas, não observou influência das fases de lactação na concentração de albumina, no entanto Raimondo et al. (2009), também trabalhando com a mesma espécie animal, verificaram diminuição nos valores desta variável na fase final de lactação.

As maiores concentrações de albumina encontradas neste trabalho na fase inicial da lactação, possivelmente foi reflexo da fase colostral, pois proteínas oriundas do sangue como a albumina, imunoglobulinas e transferrina apresen- tam concentrações mais elevadas no colostro (Leviex \& Ollier 1999). Por outro lado, Leviex \& Ollier (1999) observaram diminuição significativa na concentração de albumina nos primeiros 30 dias de lactação.

Imunoglobulinas - IgA. Não foi observado influência das fases de lactação sobre a concentração da IgA ( $P>0,3895)$, e os valores médios encontrados foram de $2,72 \mathrm{mg} / \mathrm{dL}$ (Quadro 1). No entanto, verificou-se um discreto decréscimo ao longo da lactação, conforme pode ser visualizado na Fig.2. Os achados do presente estudo assemelham-se aos verificados por Schalm et al. (1971), Sant'ana (2004) e Raimondo et al. (2009), que também relataram diminuição dos valores de IgA durante a lactação. Segundo Guidry et al. (1980) a IgA apresenta diminuição logo após o parto e durante a lactação em virtude de alterações no gradiente de concentração resultante do aumento da síntese do leite.

IgG CL. Não foi observada diferença $(P>0,3333)$ na concentração de IgG CL sendo encontrado valores médios de $45,01 \mathrm{mg} / \mathrm{dL}$, conforme Fig. 2 .

IgG CP e IgG total. Quanto a IgG de cadeia pesada, verificou-se diminuição significativa $(\mathrm{P}<0,0005)$ desta variável nos primeiros 30 dias da lactação, sendo observado o mesmo comportamento para as concentrações de IgG total $(\mathrm{P}<0,0354)$ (Quadro 1, Fig.3), com alta correlação entre ambas $(r=0,82 ; \mathrm{P}<0,0001)$, caracterizando a determinante participação de IgG de cadeia pesada na concentração final da imunoglobulina G. Portanto pode-se afirmar haver influência das fases da lactação na concentração da IgG do soro lácteo, onde verificou-se decréscimo desta classe de

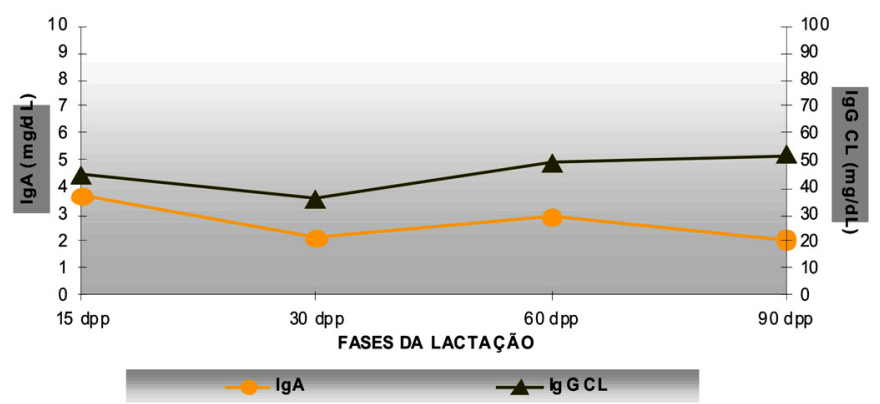

Fig.2. Valores médios da concentração da imunoglobulina IgA e IgG CL (mg/dL), obtidos por SDS-PAGE, no soro lácteo de glândulas mamárias sadias, de ovelhas Santa Inês em diferentes fases de lactação.

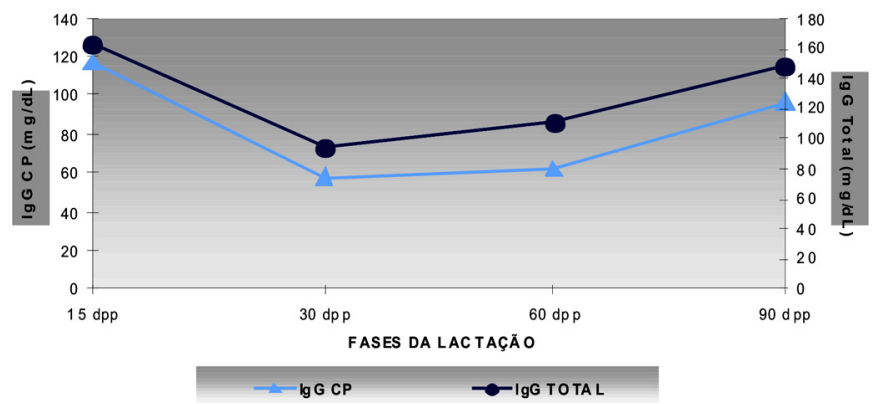

Fig.3. Valores médios da concentração da $\operatorname{IgG} \mathrm{CP}(\mathrm{mg} / \mathrm{dL})$ e IgG Total (mg/dL), obtidos por SDS-PAGE, no soro lácteo de glândulas mamárias sadias, de ovelhas Santa Inês em diferentes fases de lactação. 
imunoglobulina nos primeiros 30 dias da lactação, provavelmente ainda resíduo da fase colostral, momento em que se observa maior concentração desta imunoglobulina, predominante no colostro de ruminantes, após serem transferidas do plasma sangüíneo para a glândula mamária (Guidry et al. 1980, Caffin \& Poutrel 1988, Quiles et al. 1992, Leviex \& Ollier 1999, Sant'ana 2004, Raimondo et al. 2009).

Os valores observados da concentração de IgG foram inferiores aos relatados por Nudda et al. (2003) 383,0mg/ $\mathrm{dL}$, também trabalhando com ovelhas sadias, no entanto ressalta-se que os protocolos empregados foram distintos, apesar de ambos empregarem a técnica SDS-PAGE.

Foi observada média correlação positiva entre a IgG e a proteína total $(r=0,41 ; \mathrm{P}<0,0085)$, que pode ser justificada pela alta concentração de IgG na fase inicial da lactação como consequência da transudação das imunoglobulinas do plasma sangüíneo para o interior da glândula mamária (Schalm 1971).

Lactoferrina. Não foi constatada diferença $(P>0,1611)$ na concentração de lactoferrina ao longo da lactação, observando-se valores médios de $24,18 \mathrm{mg} / \mathrm{dL}$ (Quadro 1, Fig.4), corroborando os relatos de Nudda et al. (2003) que descreveram concentrações de $28,0 \mathrm{mg} / \mathrm{dL}$ desta proteína no soro lácteo de ovelhas da raça Sarda. Resultados semelhantes também foram descritos em vacas por Hagiwara et al. (2003) e Sant'ana (2004), que não observaram influência das fases de lactação na concentração de lactoferrina.

No último momento de observação, aos 90 dias, verifica-se valores de lactoferrina superiores aos da fase intermediária, apesar de não significativo $(\mathrm{P}>0,1611)$, o que po-

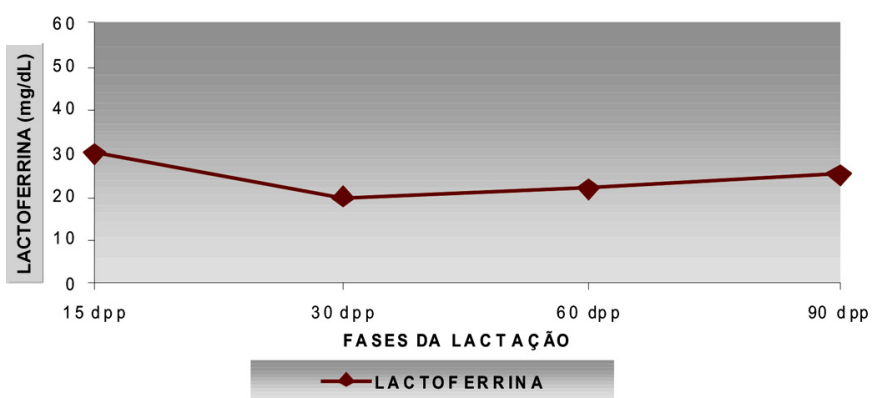

Fig.4. Valores médios da concentração de lactoferrina (mg/dL), obtidos por SDS-PAGE, no soro lácteo de glândulas mamárias sadias de ovelhas Santa Inês em diferentes fases de lactação.

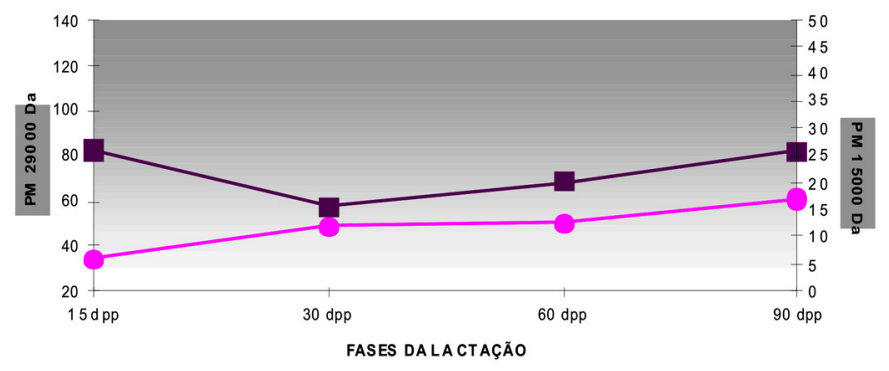

Fig.5. Valores médios da concentração das proteínas de PM 15.000 Da e PM. 29.000 Da (mg/dL), obtidos por SDS-PAGE, no soro lácteo de glândulas mamárias sadias de ovelhas Santa Inês em diferentes fases de lactação. deria estar relacionado ao início do processo de secagem, consequentemente diminuição da produção de leite, que segundo Welty et al. (1975) seria um indicador do processo de involução da glândula mamária, funcionando como um mecanismo de defesa da glândula, tendo em vista a capacidade desta proteína de ligação ao ferro.

Concentrações de lactoferrina mais elevadas no final de lactação foi relatado em cabras por Hiss et al. (2008), diferentemente do observado em vacas por Raimondo et al. (2009) e Rocha et al. (2009), que obtiveram menores valores desta proteína na fase final lactação.

Proteínas de PM 15.000 Da e PM 29.000 Da. Em ambas as proteínas identificadas pelo peso molecular não foi observada influência das fases de lactação $(P>0,4494$; $\mathrm{P}>0,4879$, respectivamente). A proteína de PM 15.000 Da apresentou valores médios de $12,10 \mathrm{mg} / \mathrm{dL}$ e a de P.M. 29.000 Da valores de 71,61 mg/dL (Fig.5). Em pesquisa compulsada não encontrou-se citações das respectivas proteínas no soro lácteo de ovelhas para confronto dos resultados, necessitando ampliar os estudos.

$\boldsymbol{\beta}$-Lactoglobulina. Em relação aos valores de $\beta$-lactoglobulina observou-se influência das diferentes fases de lactação $(\mathrm{P}<0,0005)$. As menores concentrações foram observadas aos 30 dias $(1.022,43 \mathrm{mg} / \mathrm{dL})$ e as maiores $(1.300,01 \mathrm{mg} / \mathrm{dL})$ (Quadro 1) identificadas na fase final da lactação ( 90 dias pós parto), conforme pode ser observado na Fig.6. Dentre as proteínas identificadas no soro lácteo, foi a observada em maior concentração, conforme relatado por Schalm et al. (1971). Valores inferiores desta proteína foram citados por Nudda et al. (2003) 478,0mg/dL, em ovelhas, no entanto utilizando protocolo distinto do empregado neste estudo. Em vacas, Sant'ana (2004) relatou resultados semelhantes, nos quais verifica-se maiores concentrações na fases inical e final de lactação e Raimondo et al. (2009) apenas na fase inicial no soro lácteo.

$\boldsymbol{\alpha}$-Lactoalbumina. Não foi observada diferença $(\mathrm{P}>0,0799)$ na concentração da $\alpha$-lactoalbumina durante a lactação, apresentando valores médios de $280,25 \mathrm{mg} / \mathrm{dL}$, no entanto verificase um decréscimo gradativo desta variável a partir dos 30 dias até o momento final de avaliação (Quadro 1, Fig.6). A concentração média observada desta variável foi superior a relatada por Nudda et al. (2003) de 137,0mg/dL no soro lácteo de ovelhas, que também verificaram diminuição da concentração de $\alpha$ - lactoalbumina na fase final da lactação. Pesquisas com vacas

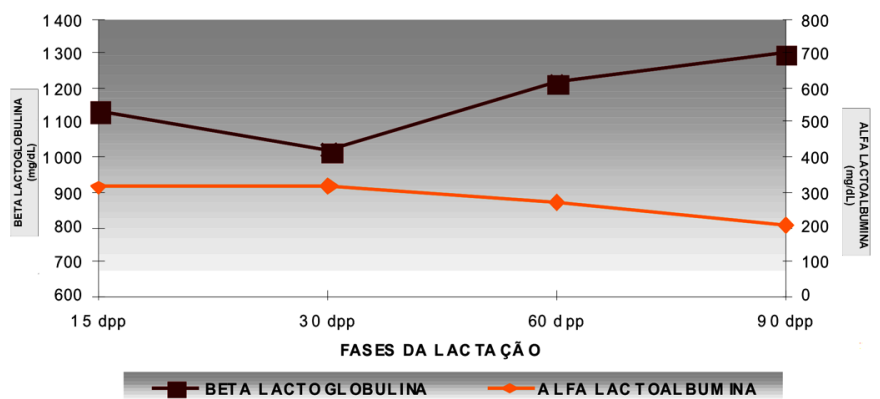

Fig.6. Valores médios da concentração da $\beta$-lactoglobulina e $\alpha$ lactalbumina (mg/dL), obtidos por SDS-PAGE, no soro lácteo de glândulas mamárias sadias de ovelhas Santa Inês em diferentes fases de lactação. 
demostraram que a concentração de $\alpha$ - lactoalbumina tende a decrescer durante a lactação, sendo esta redução atribuída à diminuição da síntese de lactose (Prosser \& McLaren 1997). A diminuição do teor da lactose na fase final da lactação também foi relatada no leite de glândulas mamárias sadias de ovelhas da raça Santa Inês (Guaraná, 2011). Por outro lado, maiores concentrações desta proteína no final da lactação foram relatados em cabras por Quiles et al. (1992) empregando o fracionamento eletroforético e em vacas por Sant'ana (2004) e Raimondo et al. (2009), estes últimos autores também na fase colostral.

\section{CONCLUSÃO}

O perfil eletroforético do soro lácteo de ovelhas da raça Santa Inês permitiu a identificação de oito proteínas, podendo-se constatar a influência das fases de lactação sobre as concentrações de albumina, imunoglobulina G e $\beta$-lactoglobulina.

Agradecimentos.- Ao Conselho Nacional de Desenvolvimento Científico Tecnológico (CNPQ, Edital Universal 14/2011) pelo auxílio financeiro e à Coordenação de Aperfeiçoamento de Ensino Superior (CAPES) pela concessão da Bolsa de Demanda Social.

\section{REFERÊNCIAS}

Adlerova L., Bartoskova A. \& Faldyna M. 2008. Lactoferrin: a review. Veterinarni Medicina, Czech Republic, 53(9):457-468.

Auldist M.J., Coats S., Rogers G.L. \& McDowell G.H. 1995. Changes in the composition of milk from healthy and mastitic dairy cows during the lactation cycle. Aust. J. Exp. Agricult. 35(4):427-436.

Bencini R. 2001. Factors affecting the quality of Ewes milk. Dairy Sheep Symposium. Wisconsin. Annals Wisconsin Sheep Dairy Cooperative, Eau Claire, Wisconsin, p.61-92.

Borkova M. \& Snaselová J. 2005. Possibilities of different animal milk detection in milk and dairy products: a review. Czech J. Food Sci. 23(2):41-50.

Burgoyne R.D. \& Duncan J. 1998. Secretion of milk proteins. J. Mammary Gland. Biol. Neoplasia 3(3):275-286.

Caffin J.P. \& Poutrel B. 1988. Physiological and pathological factors influencing bovine immunoglobulin G2 concentration in milk. J. Dairy Sci. 71:2035-2043.

Cozma A., Andrei S., Miere D., Filip L. \& Loghin F. 2011. Proteins profile in milk three species of ruminants. Not. Sci. Biol. 3:26-29.

Diffay B.C. 2005. Abordagem e exame de ovinos e caprinos, p.1-19. In: Pugh D.G. (Ed.), Clínica de Ovinos e Caprinos. Roca, São Paulo.

Fagliari J.J. \& Silva S.L. 2002. Hemograma e proteinograma plasmático de eqüinos hígidos e de eqüinos acometidos por abdômem agudo antes e após laparotomia. Arq. Bras. Med. Vet. Zootec. 54(6):559-586.

Guaraná E.L.S. 2011. Dinâmica da infecção intramamária em ovelhas da raça Santa Inês acompanhadas durante a lactação e seu impacto sobre a composição físico-química do leite. Dissertação Mestrado em Ciência Veterinária, Universidade Federal Rural de Pernambuco, Recife. 76p.

Guidry A.J., Butler J.E., Pearson R.E. \& Wetnland B.T. 1980. IgA, IgG1, IgG2, IgM in BSA serum and mammary secretion throughout lactation. Vet. Immunol. Immunopathol. 1:329-341.

Gopal P.K. \& Gill H.S. 2000. Oligosaccharides and glycoconjugates in bovine milk and colostrum. Brit. J. Nutr. 84:69-74.

Hagiwara S., Kawai K., Anari A. \& Nagahata H. 2003. Lactoferrin concentrations in milk from normal and subclinical mastitic cows. J. Vet. Med. Sci. 65:319-323.
Hiss S., Meyer T. \& Sauerwein H. 2008. Lactoferrin concentrations in goat milk throughout lactation. Small Rumin. Res. 80:87-90.

Kato K., Mori K. \& Katoh N. 1989. Different proteins patterns in normal and mastitic milks by sodium dodecyl sulfate-polyacrylamida gel electrophoresis. Jpn. J. Vet. Sci. 51(6):1275-1278.

Laemmli U.K. 1970. Cleavage of structural proteins during the assembly of the head of bacteriophage T4. Nature 227:680-685.

Levieux D. \& Ollier A. 1999. Bovine immunoglobulins G, $\beta$-lactoglobulin, $\alpha$-lactoalbumin and serum albumin in colostrums and milk during the early post partum period. J. Dairy Res. 66(3):421-430.

Little T.M. \& Hill F.J. 1978. Agricultural experimentation: Design and analysis. John Wiley and Sons, New York. 350p.

National Mastitis Council 1990. Microbiological Procedures for the Diagnosis of Bovine Udder Infection. $3^{\text {rd }}$ ed. NMC, Arlington. 34p.

Nudda A., Feligini M., Battacone G., Macciotta N.P.P. \& Pulina G. 2003. Effects of lactation stage, parity, $\alpha$-lactoglobulin genotype and milk SCC on whey protein composition in Sarda dairy ewes. Ital. J. Anim. Sci. 2:2939.

Park Y.W., Juárez M., Ramos M. \& Haenlein G.F.W. 2007. Physico-chemical characteristics of goat and sheep milk. Small Rumin. Res. 68:88-113.

Patel H.A., Anema S.G., Holroyd S.E., Singh H. \& Creamer L.K. 2007. Methods to determine denaturation and aggregation of proteins in low, medium and high heat skim milk powders. Lait 87:251-268. DOI:10.1051/ LAIT:2007027.

Prosser C.G. \& McLaren R.D. 1997. Effect of atropine on milk protein yield by dairy cows with different $\beta$-lactoglobulin phenotypes. J. Dairy Sci. 80:1281-1287.

Qian Z.Y., Jollès P., Migliore-Samour D. \& Fiat A.M. 1995. Isolation and characterization of sheep lactoferrin, an inhibitor of platelet aggregation and comparison with human lactoferrin. Biochim. Biophys. Acta 1234:25-32.

Quinn P.J., Carter M.E., Marke B. \& Carter G.R. 1994. Clinical Veterinary Microbiology, Mosby, Philadelphia. 648p.

Quiles A., Hevia M., Fuentesu F., Barcina Y. \& Ramirez A. 1992. Fraccionamiento eletroforético de las proteínas de leche de cabra de raza Murciano-Granadina. An. Vet., Murcia, 8:7-13.

Raimondo R.F.S., Miyashiro S.I. \& Birgel Jr E.H.B. 2009. Influência da fase de lactação nas proteínas do soro lácteo de vacas Jersey. Anais $8^{\circ}$ Congresso Brasileiro de Buiatria, Belo Horizonte. Ciênc. Anim. Bras. (Supl.1), p.732.

Raimondo R.F.S., Miyashiro S.I., Strangnolo C.R. \& Birgel Jr E.H.B. 2011. Efeito da infecção intramamária no proteinograma do leite de cabras. Vet. Zootec. (Supl.3), p.1048-1052.

Rocha T.G., Franciosi C., Nociti R.P., Silva P.C., Sampaio A.A M. \& Fagliari J.J. 2009. Eletroforetograma das proteínas do soro lácteo de vacas canchim primíparas e pluríparas. Anais 8 o Congresso Brasileiro de Buiatria, Belo Horizonte. Ciênc. Anim. Bras. (Supl.1), p.220.

Sant'ana V.A.C. 2004. Proteinograma do leite de vacas: padrões e variabilidade. Tese de Doutorado. Universidade de São Paulo, São Paulo. 161p.

SAS 2000. SAS User's Guide. Statistical Analysis Systems Institute Inc., Cary.

Schalm O.W., Carrol E.J. \& Jain N.C. 1971. Bovine Mastitis. Lea and Febiger, Philadelphia. $360 \mathrm{p}$.

Velasco S., Cañeque V., Diaz M.T., Perez C., Lauzurica S., Huidobro F., Manzanares C. \& Gonzales J. 2001. Producción lechera y composición lipídica de la leche de ovejas Talaveranas durante el período de lactancia. Invest. Agr., Prod. Sanid. Anim. Madri, 16(1):181-192.

Welty F.K., Larry Smith K. \& Schanbacher L.F. 1975. Lactoferrin concentration during involution of the bovine mammary gland. J. Dairy Sci. 59(2):224-231. 